Br Heart J 1989;62:415

\title{
Correspondence
}

\section{Changes in transmitral velocities with heart rate}

Sir,

During a study of changes in afterload induced by the cold pressor test, Smith et al (1989;61:344-7) recognised a relation between heart rate and transmitral velocities derived from pulsed Doppler recordings. We specifically studied the relation between transmitral velocities and differing $R R$ intervals during exercise and respiration in healthy men. ${ }^{12} \mathrm{We}$ found a clear cut linear change in peak early transmitral velocity and late (active) transmitral velocity with increasing heart rate and decreasing $\mathbf{R R}$ interval. Early velocity increased on average by $16 \%$ when heart rate increased from 53 beats per minute to 94 beats per minute but active velocity increased by $89 \%$. This led to a linear decrease in the ratio of peak early diastolic velocity to peak atrial velocity (E/A) (correlation coefficient $r=-0.99$ ). Similarly, with respiratory induced sinus arrhythmia, the E/A ratio cycled in the opposite direction to the $R R$ interval, so that as the heart rate increased the ratio fell. ${ }^{2}$

Doppler derived indices of left ventricular diastolic dysfunction that rely on transmitral velocities must take into account the relation with heart rate.

\section{K S Channer,}

Royal Hallamshire Hospital,

Glossop Road,

Sheffield S10 2JF.

J V Jones,

Bristol Royal Infirmary,

Bristol BS2 8HW.

\section{References}

1 Channer KS, Jones JV. The contribution of atrial systole to mitral diastolic blood flow increases during exercise in humans. $J$ Physiol 1989;411:53-61.

2 Channer KS, Jones JV. Changes in the pattern of transmitral blood flow during respiration in man [Abstract]. J Physiol 1988;407:21p.

This letter was shown to the authors, who reply as follows:

Sir,

We thank Dr Channer and Dr Jones for their letter and support of our observations on the influence of heart rate on Doppler measurements of transmitral flow velocity.

When we examined the effect of a short term increase in blood pressure on transmitral velocities, we found that the duration of the $R R$ interval profoundly influenced the peak atrial velocity ( $A$ or active) and its relation with early filling (A/E ratio). The studies of Channer and Jones during exercise and respiration further confirm this relation. ${ }^{12}$

Other circulatory variables such as preload that will be altered by exercise and respiration may also influence transmitral velocities. However, the studies of Channer and Jones suggest that nearly all of the change in $A$ and $A / E$ is due to changes in heart rate. ${ }^{12}$ In several studies in which abnormal transmitral velocities were attributed to left ventricular diastolic dysfunction the effect of differences in heart rate were not taken into account. ${ }^{34}$

We agree that when transmitral velocities are used as indices of left ventricular diastolic function that heart rate must be controlled or taken into account.

P E Aylward,

A E Russell,

S A Smith,

J M Sheppard,

J E Stoner,

Flinders Medical Centre,

Bedford Park,

South Australia 5042.

\section{References}

1 Channer KS, Jones JV. Changes in the pattern of transmitral blood flow during respiration in man [Abstract]. J Physiol 1988;407:21P.

2 Channer KS, Jones JV. Change with exercise in the contribution of atrial systole to diastolic blood flow across the mitral valve in man [Abstract]. $J$ Physiol (Lond) 1988;398:56P.

3 Zarich SW, Arbuckle BE, Cohen LR, Roberts M, Nesto RW. Diastolic abnormalities in young asymptomatic diabetic patients assessed by pulsed Doppler echocardiography. J Am Coll Cardiol 1988;12:114-20.

4 Phillips RA, Copland NL, Krakoff LR, et al. Doppler echocardiographic analysis of left ventricular filling in treated hypertensive patients. J Am Coll Cardiol 1987;9:317-22. 